\title{
Mechanisms of NLRP3 inflammasome activation and its role in NSAID-induced enteropathy
}

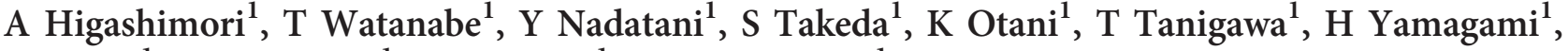 \\ M Shiba $^{1}$, K Tominaga ${ }^{1}$, Y Fujiwara ${ }^{1}$ and T Arakawa ${ }^{1}$
}

Nonsteroidal anti-inflammatory drugs (NSAIDs) induce cytokines, including tumor necrosis factor- $\alpha$ and interleukins (ILs), in the small intestine via a Toll-like receptor 4 (TLR4)-dependent pathway, leading to intestinal ulceration. Activation of the inflammasome promotes pro-caspase-1 cleavage, leading to pro-IL-1ß maturation. We examined the role of NLRP3 inflammasome in NSAID-induced enteropathy. Small intestinal damage developed $3 \mathrm{~h}$ after indomethacin administration, accompanied by increases in IL-1 $\beta$ and NLRP3 mRNA expression and mature caspase-1 and IL-1 $\beta$ levels. In vivo blocking of IL-1 $\beta$ using neutralizing antibodies attenuated indomethacin-induced damage, whereas exogenous IL-1 $\beta$ aggravated it. $N L R P 3^{-I_{-}^{-}}$and caspase- $1^{-I_{-}}$mice exhibited resistance to the damage with reduction of mature IL-1 $\beta$ production. This resistance was abolished by exogenous IL-1 $\beta$. TLR4 deficiency prevented intestinal

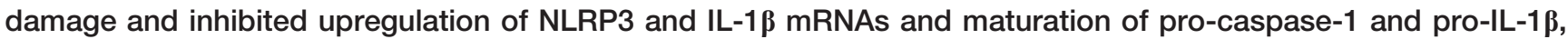
whereas TLR4 activation by its agonists exerted opposite effects. Apyrase, an adenosine triphosphate (ATP) scavenger, or Brilliant Blue $\mathrm{G}$, a purinergic $\mathrm{P} 2 \mathrm{X}_{7}$ receptor antagonist, inhibited the damage as well as caspase-1 activation and IL-1 $\mathrm{\beta}$ processing, despite there being sufficient amounts of pro-IL-1 $\beta$ and NLRP3. These results suggest that NLRP3 inflammasome-derived IL-1 $\beta$ plays a crucial role in NSAID-induced enteropathy and that both TLR4- and P2X $\mathrm{X}_{7}$ dependent pathways are required for NLRP3 inflammasome activation.

\section{INTRODUCTION}

Nonsteroidal anti-inflammatory drugs (NSAIDs) are widely used for the treatment of inflammatory conditions such as arthritis. Although these drugs provide effective pain relief and reduce inflammation-associated swelling, they can cause severe adverse effects. Of these, gastrointestinal (GI) complications such as bleeding and ulceration are the most common and significant effects observed. Recently, NSAIDs have been proven to damage the small intestine as well as upper GI tract: several studies using video capsule endoscopy have demonstrated that the prevalence of NSAID-induced small intestinal damage was $>50 \%$ in chronic users. ${ }^{1,2}$ Importantly, proton pump inhibitors, which are quite effective in preventing and healing NSAID-induced upper GI pathologies, cannot prevent NSAID-induced small intestinal damage, ${ }^{3,4}$ and more recently, both human and animal studies have raised the possibility that proton pump inhibitors might exacerbate the damage. ${ }^{5,6}$ Thus, an understanding of the pathophysiology of
NSAID-induced enteropathy is urgently required in order to develop useful drugs.

In our previous studies, we demonstrated that NSAIDs triggered inflammatory responses in the small intestine through activation of the signaling pathway of Toll-like receptor-4 (TLR4), a pattern recognition receptor (PRR), resulting in neutrophil infiltration and intestinal ulceration, ${ }^{7}$ and that lipopolysaccharide (LPS) from Gram-negative bacteria and high-mobility group box 1 (HMGB1) released from damaged intestinal epithelial cells, which are exogenous and endogenous ligands of TLR4, respectively, act in concert to elicit the intestinal inflammation that drives NSAID-induced enteropathy. ${ }^{7,8}$ During this inflammatory process, TLR4 activation signals to induce the expression of many cytokines, including tumor necrosis factor- $\alpha$ (TNF- $\alpha$ ) that has been shown to play an important role in inducing damage in both experimental and human studies. ${ }^{7,9,10}$ However, the roles of other cytokines aside from TNF- $\alpha$ remain unclear.

$\overline{1}$ Department of Gastroenterology, Osaka City University Graduate School of Medicine, Osaka, Japan. Correspondence: T Watanabe (watanabet@med.osaka-cu.ac.jp) Received 12 December 2014; accepted 24 July 2015; published online 9 September 2015. doi:10.1038/mi.2015.89 
Interleukin-1 $\beta$ (IL-1 $\beta$ ), a major proinflammatory cytokine, possesses similar biological activities to TNF- $\alpha$ and plays a key role in the pathogenesis of a variety of diseases including GI inflammation and damage. ${ }^{11-13}$ Recently, it has been demonstrated that the maturation and secretion of IL- $1 \beta$ and IL-18 are controlled by inflammasome, a large intracellular multiprotein complex. ${ }^{14}$ Inflammasomes comprised a PRR, an adaptor protein, ASC (apoptosis-associated speck-like protein containing a caspase recruitment domain), and pro-caspase- 1 . The PRRs that form inflammasomes include NOD-like receptor (NLR) family proteins such as pyrin domain-1 containing 3 (NLRP3), NLRP6, and NLR containing CARD 4 (NLRC4), and the PYHIN family proteins such as protein absent in melanoma 2 (AIM2). ${ }^{15,16}$ Recognition by NLRs or AIM2 of endogenous and exogenous signals arising from intracellular or extracellular stressors triggers the assembly of the inflammasome, leading to the cleavage and activation of pro-caspase- 1 . Once caspase- 1 is activated, it is able to promote the processing of pro-IL-1 $\beta$ and pro-IL-18 into their mature active forms. Endogenous and exogenous stressors known to activate the inflammasome include danger-associated molecular patterns such as extracellular adenosine triphosphate (ATP) and pathogen-associated molecular patterns derived from various microbial pathogens, respectively. ${ }^{15}$ Furthermore, recent studies have demonstrated that the binding of pathogen-associated molecular patterns to their corresponding TLR promotes inflammasome activation through the induction of pro-IL-1 $\beta$ and NLRs. ${ }^{17-19}$

In this study, we investigated the role of IL-1 $\beta$ and inflammasomes in NSAID-induced small intestinal damage. We also evaluated involvement of TLR4 and extracellular ATP in inflammasome activation during development of this damage.

\section{RESULTS}

\section{Small intestinal damage and cytokine expression after} indomethacin administration

Macroscopic small intestine damage, indicated by dark blue staining with $1 \%$ Evans blue, was observed from $3 \mathrm{~h}$ after the administration of indomethacin (Figure 1a), and the lesion index increased in a time-dependent manner. The mRNA levels of IL-1 $\beta$ (Figure 1c) as well as TNF- $\alpha$ (Figure 1b) in the small intestine increased significantly $6 \mathrm{~h}$ after indomethacin administration, although a significant increase in the expression level of IL-18 was observed only after $24 \mathrm{~h}$ (Figure 1d). The protein concentration of IL-1 $\beta$ in the small intestine increased from $3 \mathrm{~h}$ and then decreased to the baseline level by $24 \mathrm{~h}$ after indomethacin administration (Figure 1e). Similar to the mRNA profile, the protein concentration of IL-18 did not alter until $12 \mathrm{~h}$, and increased by $24 \mathrm{~h}$ (Figure 1f).

As the enzyme-linked immunosorbent assay (ELISA) method used for IL-1 $\beta$ in this study did not distinguish between pro-IL-1 $\beta$ and mature IL-1 $\beta$, we performed western blot analysis for cleaved (mature) IL-1 $\beta$ (p17), and found that the levels of mature IL-1 $\beta$ as well as pro-IL- $1 \beta$ in the small intestine increased from $3 \mathrm{~h}$ after indomethacin administration
(Figure 2a-c). Enhancement of caspase-1 activation was consistently detected $3 \mathrm{~h}$ after indomethacin challenge, indicated by an increase in the expression level of the p10 subunit of cleaved (active) caspase-1, whereas indomethacin administration did not affect the expression levels of pro-caspase-1 (Figure 2d,e).

\section{The role of IL-1 $\beta$ in the development of indomethacin- induced small intestinal damage}

Although exogenous administration of recombinant IL- $1 \beta$ at doses of 0.01 and $0.1 \mu \mathrm{g} \mathrm{kg}^{-1}$ did not affect indomethacininduced small intestinal damage, treatment with $1 \mu \mathrm{g} \mathrm{kg}-1$ recombinant IL- $1 \beta$ resulted in a 1.8 -fold increase in the lesion index by $24 \mathrm{~h}$ after indomethacin administration (Figure 3a,c). Exogenous IL- $1 \beta$ alone at doses of $0.01-1 \mu \mathrm{g} \mathrm{kg}^{-1}$ did not cause any intestinal damage (Figure 3a). In contrast, in vivo blocking of IL-1 $\beta$ using neutralizing antibodies attenuated intestinal damage by $53 \%$ (Figure $3 \mathbf{b}$,d).

\section{Expression of inflammasome components during the development of indomethacin-induced small intestinal damage}

The mRNA expression levels of NLRP3 were markedly increased after indomethacin administration; a significant increase was observed from $3 \mathrm{~h}$, peaking at $12 \mathrm{~h}$ (Supplementary Figure S1A online). In contrast, indomethacin treatment decreased the mRNA expression levels of other NLRs such as NLRC4 and NLRP6, and AIM2 (Supplementary Figure S1B-D). The expression levels of ASC and caspase-1 did not change throughout the experiment (data not shown).

\section{The roles of NLRP3 and caspase-1 in the development of NSAID-induced small intestinal damage}

To confirm the involvement of the NLRP3/caspase-1/IL-1 $\beta$ axis in damage development, $N L R P 3^{-1-}$ and caspase- $1^{-1-}$ mice were administered either indomethacin or diclofenac orally. As expected, the mice exhibited resistance to these NSAIDs; by $24 \mathrm{~h}$, small intestine damage caused by indomethacin was inhibited by $56 \%$ and $87 \%$ in $\mathrm{NLRP3}^{-1-}$ and caspase- $1^{-1-}$ mice, respectively. For diclofenac, damage was inhibited by $68 \%$ and $75 \%$ in $N L R P 3^{-1-}$ and caspase $1^{-1-}$ mice, respectively (Figure 4a-c). There was no significant difference between $N L R P 3^{-1-}$ and caspase- $1^{-1-}$ mice with respect to the lesion indices of both indomethacin- and diclofenac-induced damage. Previous studies demonstrated that inflammasomes such as the NLRP3 and NLRP6 inflammasomes regulated colonic microbiota. ${ }^{20-22}$ Therefore, to assess the possibility that prevention of the damage in $N L R P 3^{-1-}$ and caspase- $1^{-1-}$ mice was mediated by changes in their intestinal microbiota, either 4-week-old male NLRP3 ${ }^{-1-}$ or caspase- $1^{-1-}$ mice were cohoused with wild-type mice for 4 weeks. These mice were then challenged by indomethacin. As shown in Figure 4d,e, even after cohousing, both $N L R P 3^{-1-}$ and caspase-1 $1^{-1-}$ mice remained resistant to indomethacininduced intestinal damage, suggesting that differences in intestinal microbiota did not contribute to resistance to the damage in these two knockout mice.

Histological comparisons with wild-type mice revealed that both $N L R P 3^{-1-}$ and caspase- $1^{-1-}$ mice exhibited less severe 
a

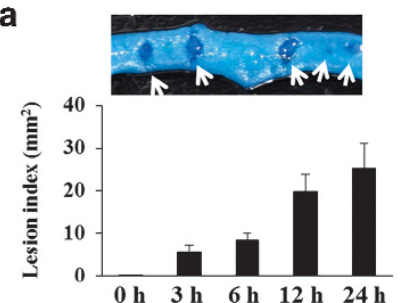

d

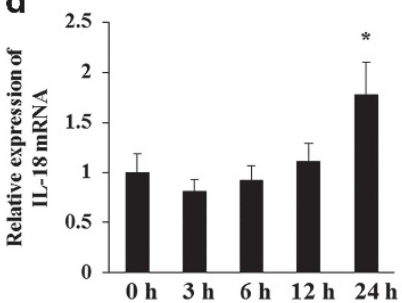

b

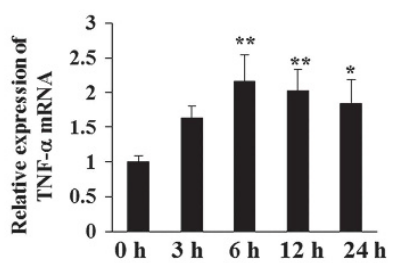

e

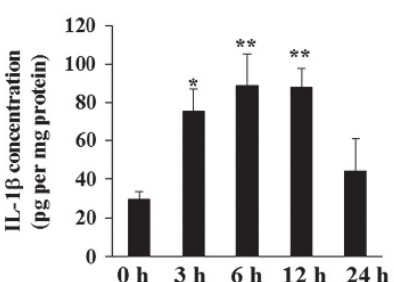

c

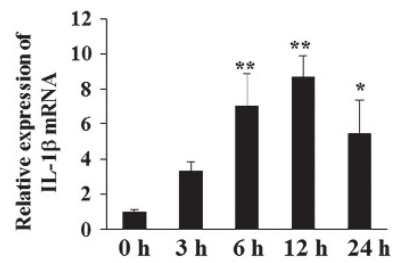

f

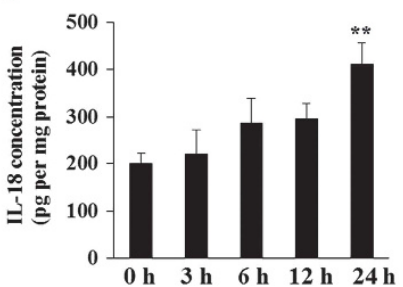

Figure 1 Small intestinal damage and cytokine expression after indomethacin administration. (a) Time course of lesion indices after indomethacin administration. The areas of macroscopically visible lesions, stained with Evans blue (arrows), were measured, summed per small intestine, and used as the lesion index. $N=5$. (b-d) The mRNA expression levels of tumor necrosis factor- $\alpha$ (TNF- $\alpha$ ), interleukin-1 $1 \beta$ (IL-1 $\beta$ ), and IL-18 as determined by quantitative reverse transcription-PCR. mRNA levels are expressed as ratios relative to the mean value for normal small intestinal tissue from untreated mice. $N=6-8$. (e, f) Protein concentrations of IL-1 $\beta$ and IL-18 in the small intestine were measured by enzyme-linked immunosorbent assay. $N=5-8$. ${ }^{\star} P<0.05,{ }^{*} P<0.01$ vs. untreated control (0 h group). Data in a-f are representative of three independent experiments.
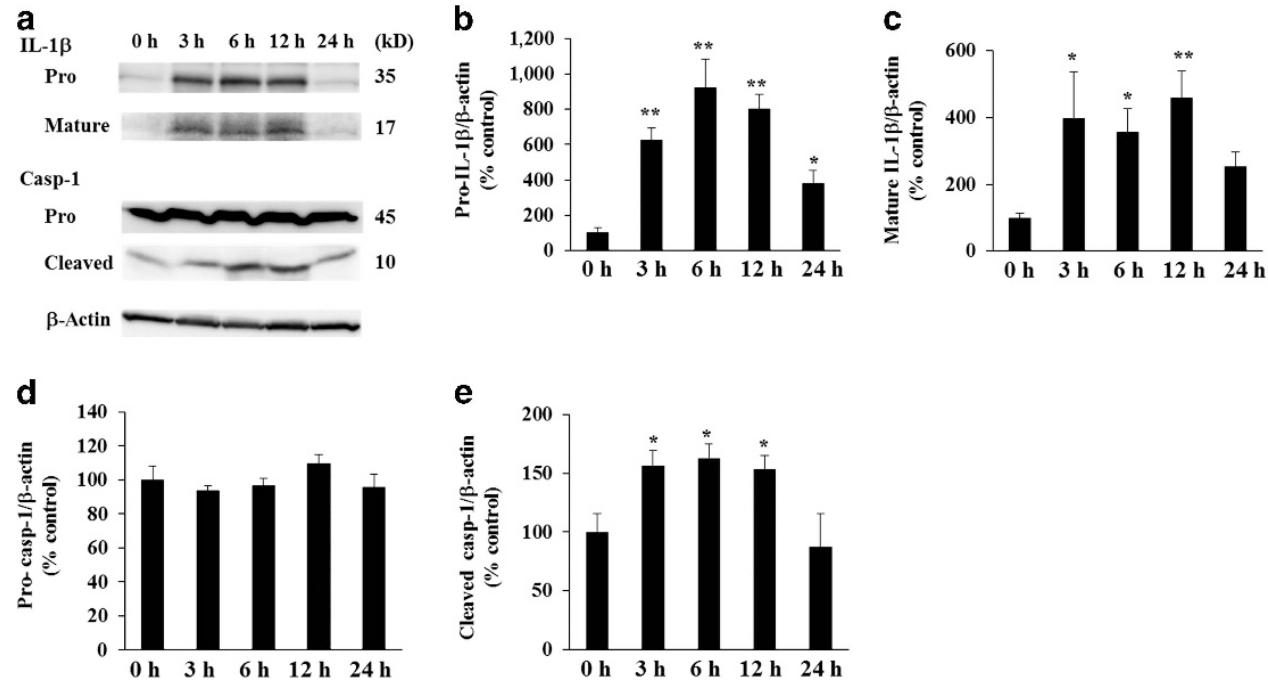

Figure 2 Activation of interleukin-1 $($ IL-1 $\beta$ ) and caspase-1 (Casp-1) during the development of indomethacin-induced small intestinal damage. Expression levels of IL-1 $\beta$ and Casp-1 in the small intestine were evaluated by western blot analysis. (a) Representative western blots for IL-1 $\beta$ and Casp-1. (b-e) Expression levels of (b) pro-IL-1 $\beta$, (c) mature IL-1 $\beta$, (d) pro-Casp-1, and (e) cleaved Casp-1 were normalized to that of $\beta$-actin. Data are from a single experiment, representative of at least two independent experiments. $N=6$. ${ }^{\star} P<0.05$, ${ }^{\star \star} P<0.01$ vs. untreated control ( $0 \mathrm{~h}$ group).

mucosal inflammation and prevention of development of deep ulceration with a decrease in size and numbers of ulcerated area $24 \mathrm{~h}$ after NSAID challenge (Figure 4f). Administration of the vehicle, instead of indomethacin, did not cause any macroscopic and microscopic intestinal damage by $24 \mathrm{~h}$ in $N L R P 3^{-I-}$ and caspase- $1^{-I-}$ mice, as well as wild-type mice.

Next, we examined the effect of the genetic depletion of NLRP 3 and caspase- 1 on IL- $1 \beta$ expression. In comparison with wild-type mice, the increased expression of both IL-1 $\beta$ mRNA and protein levels, as determined by real-time quantitative reverse transcription-PCR (RT-PCR, Figure 5a) and ELISA (Figure 5b), respectively, was significantly inhibited in both
$N L R P 3^{-1-}$ and caspase $-1^{-1-}$ mice $6 \mathrm{~h}$ after indomethacin administration. Similar to wild-type mice, both $N L R P 3^{-1-}$ and caspase- $1^{-1-}$ mice exhibited a marked increase in pro-IL$1 \beta$ protein levels in the small intestine, but the increase in the level of mature IL-1 $\beta$ induced by indomethacin administration was completely suppressed in these mice (Figure $5 \mathbf{c}-\mathbf{e}$ ). Furthermore, the increase in the level of cleaved caspase- 1 was also completely suppressed in $N L R P 3^{-/-}$mice despite sufficient levels of pro-caspase-1 (Figure 5f,g).

To confirm that the resistance to NSAID-induced small intestinal damage in NLRP3 ${ }^{-1-}$ and caspase- $1^{-1-}$ mice was due to a deficiency in mature IL-1 $\beta$, these mice were given an 


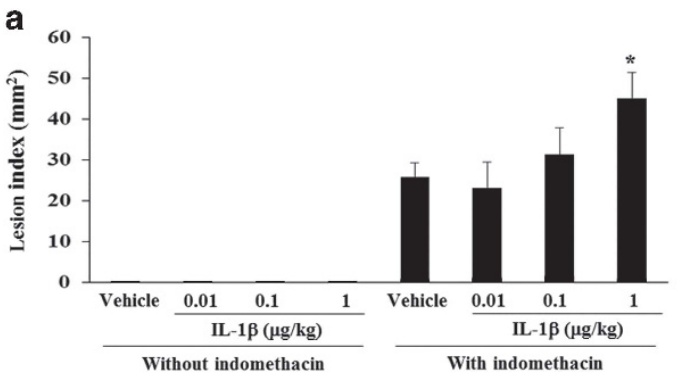

b

C

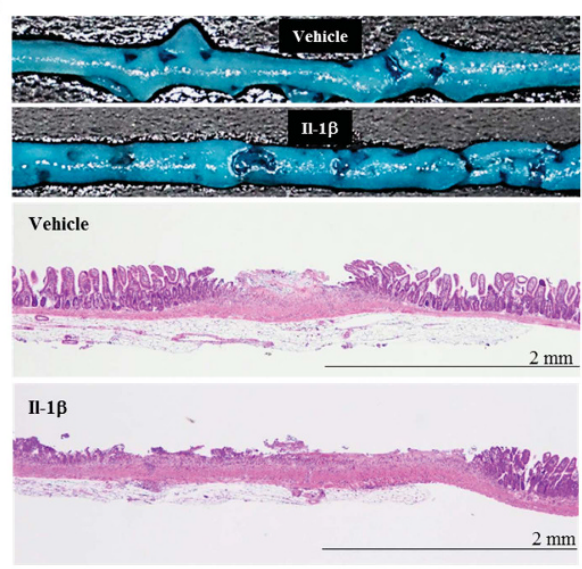

d

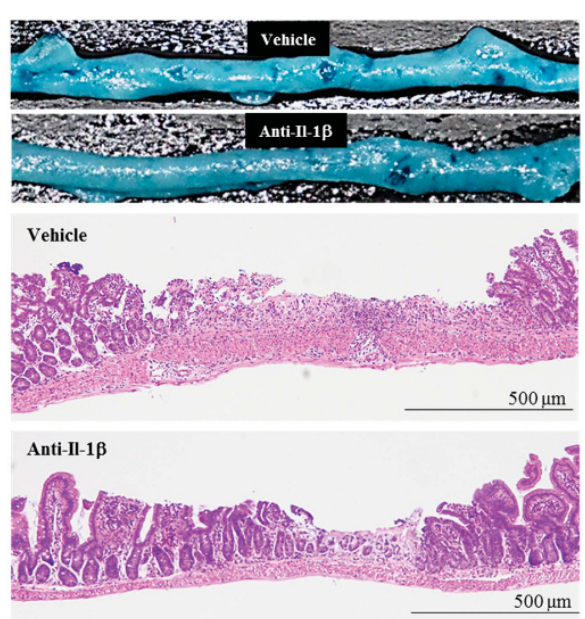

Figure 3 The role of interleukin-1 $\beta$ (IL-1 $\beta$ ) in the development of indomethacin-induced small intestinal damage. (a) Mice were intraperitoneally injected with mouse recombinant IL-1 $\beta$ at doses of $0.01-1 \mu \mathrm{g} \mathrm{kg}^{-1}$ or vehicle $3 \mathrm{~h}$ after indomethacin treatment, whereas some mice were given recombinant IL-1 $\beta$ alone. $N=5-7$. (b) Mice were intraperitoneally administered neutralizing goat anti-IL-1 $\beta$ polyclonal antibody or vehicle at a dose of $100 \mu \mathrm{g}$ per mouse 0 and $6 \mathrm{~h}$ after indomethacin treatment. $N=6$. ${ }^{*} P<0.05 \mathrm{vs}$. vehicle-treated group. (c, d) Representative images of macroscopically visible lesions stained with Evans blue and histological staining $24 \mathrm{~h}$ after indomethacin administration in mice given recombinant IL-1 $\beta$ (c) or neutralizing anti-IL-1 $\beta$ antibody (d). Data in $\mathbf{a}-\mathbf{d}$ are representative of three independent experiments.

intraperitoneal injection of mouse recombinant IL-1 $\beta$ at a dose of $0.1 \mu \mathrm{g} \mathrm{kg}^{-1} 3 \mathrm{~h}$ after indomethacin treatment. The resistance in $N L R P 3^{-1-}$ and caspase- $1^{-1-}$ mice was abolished by supplementation with IL-1 $\beta$; the lesion indices for indomethacin-induced damage were similar in wild-type mice with or without IL-1 $\beta$ supplementation, and IL-1 $\beta$-supplemented $N L R P 3^{-1-}$ and caspase- $1^{-1-}$ mice (Figure 5h).

\section{Localization of IL-1及, NLRP3, and cleaved caspase-1 in damaged small intestinal mucosa and roles of macrophages in the damage}

Immunoreactivity for IL-1 $\beta$ and cleaved caspase- 1 was observed mainly in inflammatory cells (Figure 6a,c). Double staining of IL- $1 \beta$ or cleaved caspase- 1 with F4/80 demonstrated that many macrophages in the lamina propria expressed IL- $1 \beta$ or cleaved caspase-1. NLRP3 was diffusely expressed in many cell types including epithelial cells and inflammatory cells such as macrophages (Figure 6b). Staining of intestinal tissue from $N L R P 3^{-1-}$ or caspase- $^{-1-}$ mice with an anti-NLRP3 antibody or anti-cleaved caspase-1 antibody, respectively, revealed no positive signal, confirming the specificity of these antibodies (Supplementary Figure S2).

Next, we investigated the roles of macrophages in indomethacin-induced intestinal damage. Mice with macrophage depletion by clodronate-encapsulated liposomes exhibited less severe damage. The mean lesion index was inhibited by $84 \%$ compared with vehicle-treated mice (Figure 7a). Furthermore, macrophage depletion markedly inhibited indomethacininduced increase in mature IL-1 $\beta$ expression (Figure $7 \mathbf{b}, \mathbf{c}$ ).

\section{The role of TLR4 in the activation of the NLRP3 inflammasome during development of NSAID-induced enteropathy}

Next, we examined the role of TLR4 in inflammasome activation in NSAID-induced enteropathy. Indomethacininduced small intestinal damage was inhibited by $65 \%$ in TLR4 ${ }^{-1-}$ mice $24 \mathrm{~h}$ after indomethacin administration, but this protective effect of TLR4 deficiency on the damage was abolished by exogenous IL-1 $\beta$ (Supplementary Figure S3A). TLR4 depletion prevented the increase in IL-1 $\beta$ and NLRP3 mRNA expression levels in the small intestine at $6 \mathrm{~h}$, whereas TLR4 signaling activation by LPS and recombinant HMGB1 resulted in the enhancement of mRNA expression (Supplementary Figure S3B,C), with a 1.7 -fold and 1.6-fold increase in the lesion index by $24 \mathrm{~h}$, respectively. Genetic depletion of TLR4 also prevented indomethacininduced increases in the expression of mature IL-1 $\beta$ and cleaved caspase-1 at $6 \mathrm{~h}$ (Supplementary Figure S3D-H). 
a
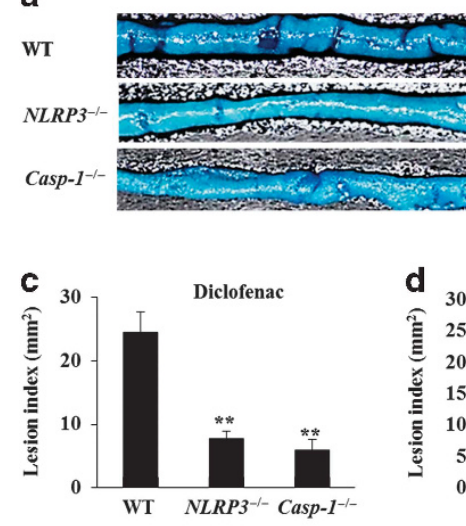

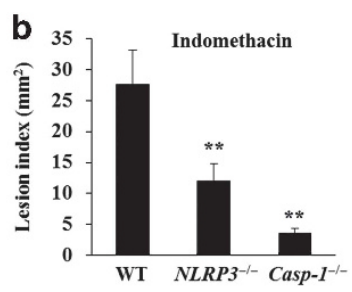

e
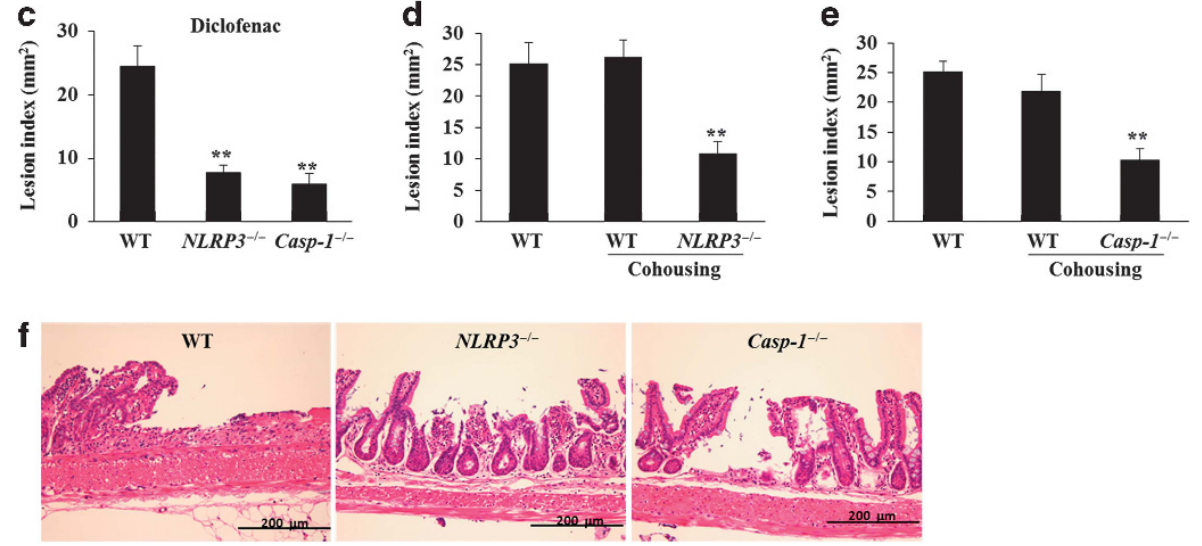

Figure 4 The roles of NLRP3 and caspase-1 (Casp-1) in the development of nonsteroidal anti-inflammatory drug (NSAID)-induced small intestinal damage. Wild-type (WT), NLRP3 ${ }^{-1-}$, and caspase- $1^{-1-}\left(\right.$ Casp-1 $\left.1^{-1-}\right)$ mice were administered $10 \mathrm{mg} \mathrm{kg}^{-1}$ indomethacin or $60 \mathrm{mg} \mathrm{kg}{ }^{-1}$ diclofenac by gavage and were killed $24 \mathrm{~h}$ later. In addition, either 4-week-old $N L R P 3^{-1}$ or Casp-1 ${ }^{-1}$ mice were cohoused with WT mice for 4 weeks. Then, these mice were challenged by indomethacin. (a-c) Areas of macroscopically visible lesions, stained with Evans blue (a), were measured, summed per small intestine, and used as the lesion index (b, $\mathbf{c}) . N=5-9 .{ }^{* \star} P<0.01 \mathrm{vs}$. WT. (d, e) Effect of cohousing with WT mice on prevention of the intestinal damage in $N L R P 3^{-1-}$ and Casp $-1^{-1-}$ mice. $N=6,{ }^{* *} P<0.01$ vs. WT. (f) Histological findings $24 \mathrm{~h}$ after indomethacin administration. Data in a-d and $\mathbf{f}$ are representative of three experiments; data in e are representative of two experiments.
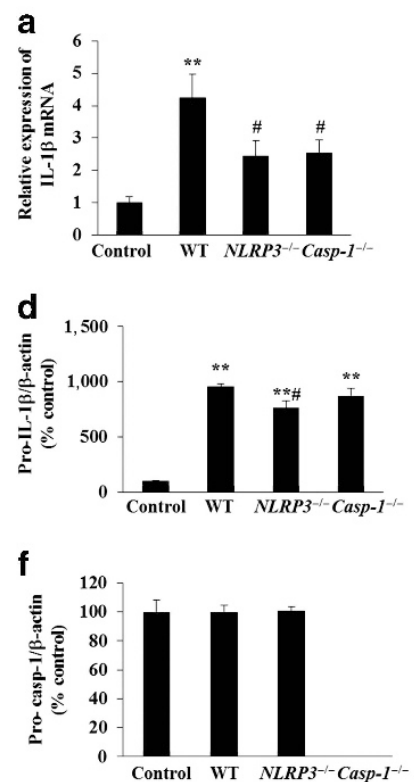
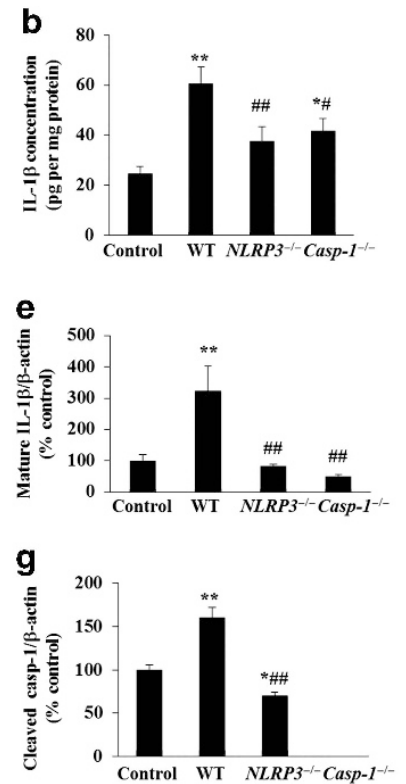
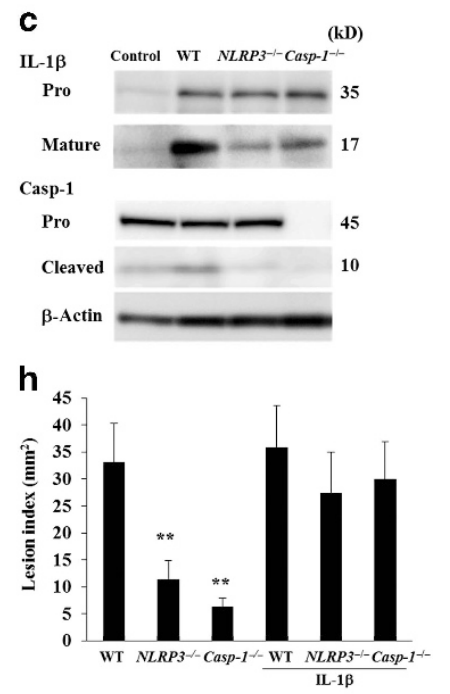

Figure 5 The roles of NLRP3 and caspase-1 (Casp-1) in the activation of interleukin-1 $\beta$ (IL-1 $\beta$ ) in indomethacin-induced small intestinal damage. Wild-type (WT), NLRP3 ${ }^{-1-}$, and caspase-1-1- $\left(\right.$ Casp-1 $\left.^{-1-}\right)$ mice were administered $10 \mathrm{mg} \mathrm{kg}^{-1}$ indomethacin by gavage and killed $24 \mathrm{~h}$ later. $(\mathbf{a}, \mathbf{b}) \mathrm{IL}-1 \beta$ expression level was determined by quantitative reverse transcription-PCR, whereas the concentration of IL-1 $\beta$ was measured by enzymelinked immunosorbent assay. $N=5-9$. (c) Representative western blots for IL-1 $\beta$ and Casp-1. (d-g) Expression levels of (d) pro-IL-1 $\beta$, (e) mature IL-1 $\beta$, (f) pro-Casp-1, and (g) cleaved Casp-1 normalized to $\beta$-actin. Data are from a single experiment, representative of at least two independent experiments. $N=4-9$. ${ }^{*} P<0.05$, ${ }^{* \star} P<0.01$ vs. untreated control; ${ }^{\#} P<0.05$, ${ }^{\# \#} P<0.01$ vs. WT mice. (h) The effect of exogenous IL- $1 \beta$ on indomethacin-induced damage in $N L R P 3^{-1-}$ and Casp-1 $1^{-1-}$ mice. WT, NLRP3 ${ }^{-1-}$, and Casp $-1^{-1-}$ mice were given intraperitoneal injection of mouse recombinant IL-1 $\beta$ at a dose of $0.1 \mu \mathrm{g} \mathrm{kg}^{-1} 3 \mathrm{~h}$ after indomethacin treatment. $N=5-7 .{ }^{\star \star} P<0.01 \mathrm{vs}$. WT mice. Data in a-g are representative of at least three experiments; data in $\mathbf{h}$ are representative of two experiments. 
a

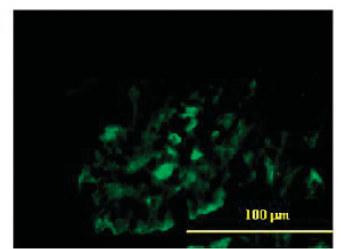

IL-1 $\beta$

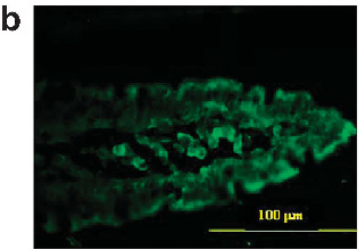

NLRP3

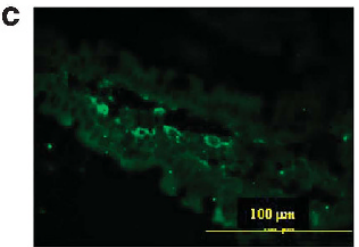

Cleaved caspase-1

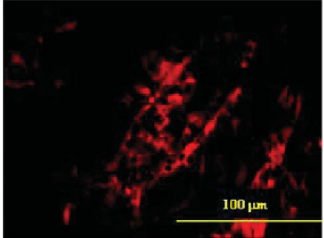

F4/80

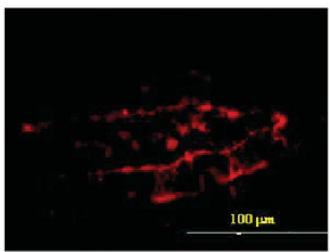

F4/80

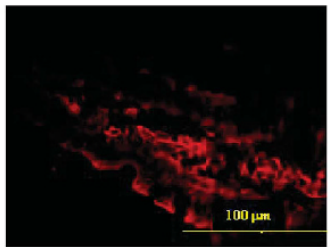

F 4/80

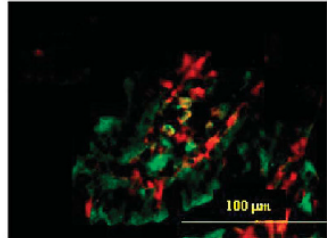

Merge

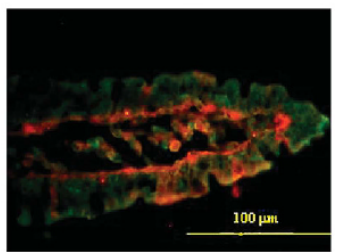

Merge

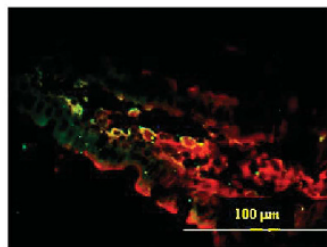

Merge

Figure 6 Localization of interleukin-1 $\beta$ (IL-1 $\beta$ ), NLRP3, and cleaved caspase-1 in damaged small intestinal mucosa. Expression of (a) IL-1 $\beta$, (b) NLRP3, and (c) cleaved caspase-1 and their colocalization with F4/80 (a marker of mature macrophages) were determined using an immunofluorescence method. Immunofluorescent images are representative of three independent experiments.
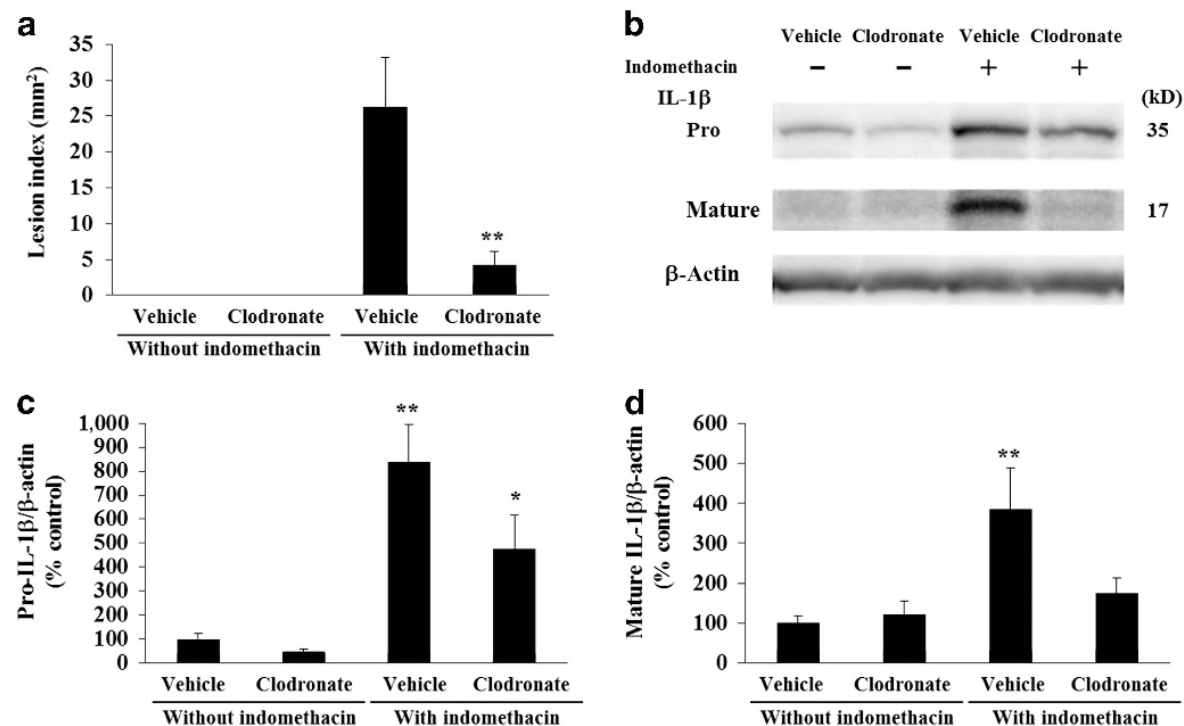

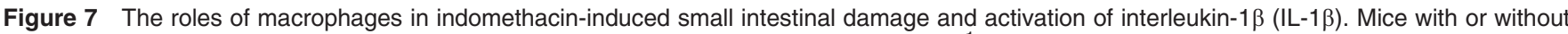
macrophage depletion by clodronate-encapsulated liposomes were administered $10 \mathrm{mg} \mathrm{kg}^{-1}$ indomethacin by gavage. Some mice were killed $6 \mathrm{~h}$ after treatment, and the expression levels of IL-1 $\beta$ were measured. The remaining mice were killed $24 \mathrm{~h}$ later to measure the lesion index. (a) The effect of macrophage depletion on indomethacin-induced small intestinal damage. $N=6$. ${ }^{* \star} P<0.01$ vs. vehicle-treated mice. (b) Representative IL-1 $\beta$ western blot. (c, d) Expression levels of pro-IL-1 $\beta$ and mature IL-1 $\beta$ normalized to $\beta$-actin. Data are from a single experiment, representative of three independent experiments. $N=5-6 .{ }^{*} P<0.05,{ }^{\star \star} P<0.01$ vs. vehicle-treated control. Data in a are representative of three experiments; data in $\mathbf{b}-\mathbf{d}$ are representative of two experiments.

The role of $\mathrm{P}_{2} \mathrm{X}_{7}$ receptor in activation of the NLRP3 inflammasome during the development of NSAID-induced enteropathy

Finally, we examined the role of the axis of ATP/P2X $\mathrm{X}_{7}$ receptor (a purinergic receptor that mediates at least partially the biological actions of extracellular ATP) in the activation of the NLRP3 inflammasome and indomethacin-induced damage. Brilliant Blue $\mathrm{G}$ (a selective antagonist of $\mathrm{P}_{2} \mathrm{X}_{7}$ receptor) and apyrase (an enzyme that inactivates extracellular ATP) both inhibited the increase in the expression levels of mature IL- $1 \beta$ 

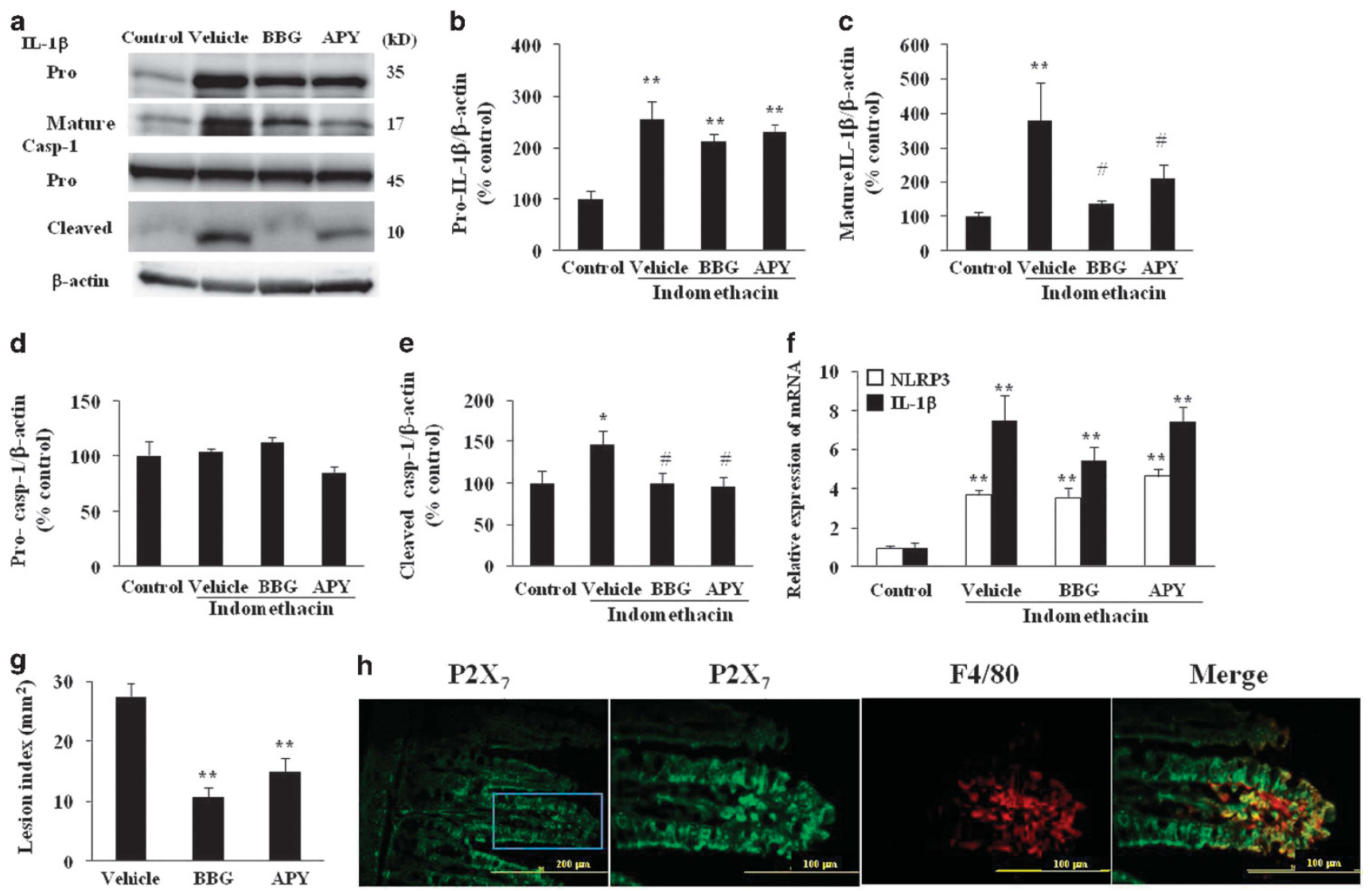

Figure 8 The roles of $\mathrm{P}_{2} \mathrm{X}_{7}$ receptor in the activation of the NLRP3 inflammasome during the development of nonsteroidal anti-inflammatory drug (NSAID)-induced enteropathy. Mice were intraperitoneally given apyrase (APY) or Brilliant Blue G (BBG) after indomethacin treatment. Some of the mice were killed $6 \mathrm{~h}$ later and the expression levels of interleukin-1 $\beta$ (IL-1 $\beta$ ) and components of the NLRP 3 inflammasome were measured. The remaining mice were killed $24 \mathrm{~h}$ later to measure the lesion index. (a) Representative western blots for IL-1 $\beta$ and caspase-1 (Casp-1). (b-e) Expression levels of (b) proIL-1 $\beta$, (c) mature IL-1 $\beta$, (d) pro-Casp-1, and (e) cleaved Casp-1 normalized to $\beta$-actin. Data are from a single experiment, representative of three independent experiments. $N=4-7$. ${ }^{*} P<0.05$, ${ }^{\star *} P<0.01$ vs. untreated control, ${ }^{\#} P<0.05$ vs. vehicle-administered mice with indomethacin treatment. (f) The role of $\mathrm{P}_{2} \mathrm{X}_{7}$ receptor in the expression of NLRP3 and IL-1 $\beta . N=7-8$. ${ }^{\star \star} P<0.01$ vs. untreated control. (g) The effect of blocking P2X signaling on indomethacin-induced small intestinal damage. $N=6$. ${ }^{\star \star} P<0.01$ vs. vehicle-treated control. (h) Localization of $P 2 X_{7}$ receptors in damaged small intestinal mucosa. Data in $\mathbf{a}-\mathbf{f}$ and $\mathbf{h}$ are representative of three experiments; data in $\mathbf{g}$ are representative of two experiments.

and cleaved caspase- 1 in the small intestine $6 \mathrm{~h}$ after indomethacin administration (Figure 8a-e) without affecting the mRNA expression of NLRP3 and IL-1 $\beta$ (Figure 8f). In addition, Brilliant Blue $\mathrm{G}$ and apyrase significantly prevented intestinal damage at 24 h by $61 \%$ and $46 \%$, respectively (Figure $\mathbf{8 g}$ ).

Immunofluorescence assays demonstrated that $\mathrm{P}_{2} \mathrm{X}_{7}$ was expressed on inflammatory cells, epithelial cells, and endothelial cells in the damaged small intestine. Double staining of $\mathrm{P}_{2} \mathrm{X}_{7}$ with F4/80 showed that the majority of $\mathrm{P}_{2} \mathrm{X}_{7}$-positive inflammatory cells were macrophages (Figure $\mathbf{8 h}$ ).

\section{DISCUSSION}

In this study, we demonstrated that indomethacin damages the small intestine coupled with the promotion of caspase- 1 and IL- $1 \beta$ maturation. Treatment with recombinant IL- $1 \beta$ aggravated intestinal damage, whereas in vivo blocking of IL-1 $\beta$ using neutralizing antibodies inhibited it. Furthermore, NLRP3 ${ }^{-I^{-}}$ and caspase- $1^{-1-}$ mice exhibited less severe damage and lower production levels of mature IL-1 $\beta$. These findings clearly indicate that IL-1 $\beta$ plays a crucial role in NSAID-induced enteropathy. Interestingly, the expression of IL-18, which is also activated by inflammasomes ${ }^{14}$ and possesses proinflammatory effects, $^{23}$ did not increase until $24 \mathrm{~h}$ after indomethacin challenge, when the damage was complete. Furthermore, the resistance to intestinal damage in mice deficient for NLRP3 and caspase- 1 was abolished by supplementation with a low dose of exogenous IL- $1 \beta\left(0.1 \mu \mathrm{g} \mathrm{kg}^{-1}\right)$, and this did not affect the severity of the damage in wild-type mice. This suggests that resistance in the NLRP3- and caspase-1-deficient mice is due to a deficiency in mature IL-1 $\beta$. Taken together, it seems that IL-18 plays a minor role, if any, in the development of NSAID-induced small intestinal damage. To the best of our knowledge, this is the first report demonstrating the importance of the inflammasome/caspase-1/IL-1 $\beta$ axis in NSAID-induced enteropathy.

Canonical inflammasomes can produce mature IL-1 $\beta$ via processing of pro-caspase- 1 in response to various danger signals. ${ }^{24}$ Damaged intestinal mucosa is exposed to various stressors including microbial pathogen-associated molecular patterns and endogenous danger-associated molecular patterns 
that can activate multiple inflammasomes, ${ }^{24,25}$ suggesting that other inflammasomes in addition to the NLRP3 inflammasome might be activated during the development of NSAID-induced enteropathy. However, our results reveal that among the examined PRRs involved in inflammasome activation, NLRP3 was the only factor that increased after indomethacin challenge; the expression levels of other PRRs such as NLRP6, NLRC4, and AIM2 decreased. Furthermore, the increase in the production of mature IL- $1 \beta$ was completely inhibited in $N L R P 3^{-1-}$ mice; the level of mature IL-1 $\beta$ in NLRP3 ${ }^{-1-}$ mice $6 \mathrm{~h}$ after indomethacin administration was comparable to that of wild-type mice without indomethacin treatment. Together with the findings that in both indomethacin- and diclofenacinduced damage, the lesion indices did not differ between NLRP $3^{-1-}$ and caspase- $1^{-/-}$mice, these results strongly suggest that among the inflammasomes, the NLRP3 inflammasome plays a major role in the pathogenesis of NSAIDinduced enteropathy.

Our findings concur with previous studies demonstrating that the NLRP3 inflammasome plays a crucial role in the induction of inflammation and damage in several organs, including the heart, ${ }^{26}$ lung, ${ }^{27}$ liver, ${ }^{28}$ kidney, ${ }^{29}$ and colon. ${ }^{30}$ However, the role of the NLRP3 inflammasome in tissue damage, particularly in the lower GI tract, is conflicting and inconclusive. Bauer et al. ${ }^{30}$ reported that NLRP3-deficient mice developed less severe dextran sulfate sodium-induced colitis than wild-type mice and produced lower levels of proinflammatory cytokines in colonic tissue. Furthermore, genetic depletion of capsase-1 as well as treatment with IL-1 receptor antagonists reduced the severity of dextran sulfate sodium-induced colitis in mice, ${ }^{31}$ and blocking inflammasome activation using caspase-1 inhibitor ameliorated spontaneous colitis in IL-10-deficient mice with a reduction of IL-1 $\beta$ expression, ${ }^{32}$ suggesting that the NLRP3 inflammasome/IL-1 $\beta$ axis may mediate colitis.

In contrast, conflicting results have been reported concerning the role of inflammasome components, including NLRP3, caspase-1, and ASC in colitis; several groups demonstrated that genetic depletion of NLRP3 resulted in hypersensitivity to experimental colitis induced by dextran sulfate sodium ${ }^{20,33,34}$ and 2,4,6-trinitrobenzene sulfonate. ${ }^{20,34}$ In addition, mice lacking caspase-1 and ASC were found to be highly susceptible to dextran sulfate sodium-induced colitis compared with wildtype animals. ${ }^{20,33,35}$ The phenotype in caspase- $1^{-1}$ mice was rescued by administration of exogenous IL-18, ${ }^{20,35}$ suggesting IL-18 significantly contributes to the inflammasome's protective effects on colitis. IL-18 is thought to mediate this protection via several mechanisms including maintenance of intestinal homeostasis ${ }^{20}$ and promotion of reepithelialization. ${ }^{35}$ In this study, mice given indomethacin displayed a rapid and marked increase in IL- $1 \beta$ expression in the small intestine, but only a mild increase in IL-18 expression in the late phase of injury. Therefore, the NLRP3 inflammasome may play a proinflammatory deleterious role, instead of a protective role, in NSAIDinduced enteropathy via the production of mature IL- $1 \beta$. The reason for the differences in the dynamics of these two cytokines is unclear.
Extensive research has revealed that two signals are required for the activation of the NLRP3 inflammasome. The binding of TLR ligands such as pathogen-associated molecular patterns and danger-associated molecular patterns or cytokines such as TNF- $\alpha$ and IL- $1 \beta$ to their corresponding receptors provides the initial signal by triggering nuclear factor- $\kappa \mathrm{B}-$ mediated upregulation of NLRP3 and pro-IL- $1 \beta .{ }^{18,36}$ The second signal that triggers the activation of NLRP3, assembly of the inflammasome complex, and finally the processing of pro-caspase- 1 is provided by danger signals such as extracellular ATP, certain bacterial toxins, amyloid $\beta$ aggregates, or particulate matter such as crystalline forms of monosodium urate, asbestos, and silica. ${ }^{37}$ In this study, TLR4-deficient mice exhibited inhibition of mRNA expression for NLRP3 and IL-1 $\beta$ after indomethacin challenge, whereas activation of TLR4 by LPS or HMGB1 resulted in enhancement of their expression levels. These results clearly indicate that the TLR4-dependent pathway mediates the initial signal during the development of NSAIDinduced enteropathy. As pro-IL-1 $\beta$ is not constitutively expressed and the basal levels of NLRP3 are inadequate for efficient inflammasome formation, ${ }^{18,38}$ it is conceivable that TLR4-deficient mice failed to activate the NLRP3 inflammasome after indomethacin challenge because of insufficient levels of pro-IL-1 $\beta$ and NLRP3.

In contrast, we found that despite sufficient levels of the inflammasome components, including NLRP3 and an inflammasome substrate, pro-IL-1 $\beta$ mice treated with Brilliant Blue $G$ and apyrase could not activate the inflammasome, suggesting a key role for the $\mathrm{ATP} / \mathrm{P} 2 \mathrm{X}_{7}$ axis in activation of the second signal. The $\mathrm{P}_{2} \mathrm{X}_{7}$ receptor is an ATP-gated ion channel primarily expressed on cells of the immune system. Upon ATP stimulation, the $\mathrm{P} 2 \mathrm{X}_{7}$ receptor opens a cation channel that induces $\mathrm{K}^{+}$efflux, a phenomenon that appears to be required for NLRP3 inflammasome activation. ${ }^{39,40}$ In a previous study, we demonstrated that damaged and necrotic epithelial cells in the small intestine released an endogenous danger-associated molecular pattern HMGB1 from the early phase of NSAID-induced enteropathy. ${ }^{8}$ As these cells can release ATP into the extracellular space, ${ }^{41}$ we can hypothesize that in NSAID-induced intestinal damage, macrophages in which TLR4 signaling has been activated by bacterial LPS and/or HMGB1 are stimulated by extracellular ATP from damaged epithelial cells through the $\mathrm{P}_{2} \mathrm{X}_{7}$ receptors, resulting in NLRP3 inflammasome activation and IL- $1 \beta$ release. The findings that the expression of cleaved caspase- 1 and $\mathrm{P} 2 \mathrm{X}_{7}$ receptor was mainly observed in macrophages in the damaged intestinal epithelium and that macrophage depletion markedly inhibited the damage and expression of mature IL-1 $\beta$ support our hypothesis, and strongly suggest that, in NSAID-induced enteropathy, activation of the NLRP3 inflammasome occurred mainly in macrophages, leading to intestinal damage.

In conclusion, our results suggest that NLRP3 inflammasome-derived IL- $1 \beta$ plays a crucial role in NSAID-induced small intestinal damage, and that both TLR4- and P2X $\mathrm{X}_{7}$-dependent signaling pathways are required for NLRP3 inflammasome activation during this damage. Thus, the 
NLRP3 inflammasome/IL-1 $\beta$ axis could be a target for treatment of NSAID-induced enteropathy.

\section{METHODS}

Animals and induction of experimental small intestinal damage. NLRP3 ${ }^{-1-}$ and caspase- $1^{-1-}$ mice on a C57BL/6 background were purchased from Jackson Laboratory (Bar Harbor, ME). TLR $4^{-1-}$ mice that were backcrossed 8 times on the C57BL/6 background, originally generated by Dr S. Akira (Osaka University, Osaka, Japan), were obtained from Oriental Bioservice (Kyoto, Japan). Wild-type C57BL/ 6 mice were purchased from Charles River Japan (Atsugi, Japan) and used as the control strain for these three knockout mouse strains.

To induce small intestinal injury, nonfasted mice were administered $10 \mathrm{mg} \mathrm{kg}^{-1}$ indomethacin (Sigma-Aldrich, St Louis, MO) in a $0.5 \%$ carboxymethylcellulose solution by gavage and were killed $0,3,6$, or $24 \mathrm{~h}$ later. In some experiments, mice were administered $60 \mathrm{mg} \mathrm{kg}^{-1}$ diclofenac (Sigma-Aldrich) instead of indomethacin. In each case, to delineate the damage, 1\% Evans blue was injected intravenously 30 min before killing, and the small intestine was opened along the antimesenteric attachment and examined for damage under a dissecting microscope with square grids $(\times 10)$. The area $\left(\mathrm{mm}^{2}\right)$ of macroscopically visible lesion was measured, summed per small intestine, and used as the lesion index. In this study, specific pathogenfree 10-week-old male animals were used. All animals were housed in polycarbonate cages with paper chip bedding. The cages were located in an air-conditioned biohazard room with a 12-h light/dark cycle. All experimental procedures were approved by the animal care committee of the Osaka City University Graduate School of Medicine.

Experimental groups. To investigate the role of IL-1 $\beta$ in the development of NSAID-induced small intestinal damage, mice received intraperitoneal injections of mouse recombinant IL-1 $\beta$ (0.01-1 $\mu \mathrm{g} \mathrm{kg}^{-1}$; R\&D Systems, Minneapolis, MN) or vehicle (saline only) $3 \mathrm{~h}$ after indomethacin treatment. In addition, mice were intraperitoneally administered neutralizing goat anti-IL-1 $\beta$ polyclonal antibody or normal goat IgG (both from R\&D Systems) at a dose of $100 \mu \mathrm{g}$ per mouse at 0 and $6 \mathrm{~h}$ after indomethacin treatment.

To elucidate the involvement of the ATP/P2X $\mathrm{X}_{7}$ axis in the pathogenesis of NSAID-induced enteropathy, potato apyrase $(25 \mathrm{U}$ per mouse; Sigma-Aldrich), an enzyme that inactivates extracellular ATP, or Brilliant Blue G (45 $\mathrm{mg} \mathrm{kg}^{-1}$; Abcam, Cambridge, MA), a selective antagonist of $\mathrm{P} 2 \mathrm{X}_{7}$ receptor, were intraperitoneally administered 3 and $6 \mathrm{~h}$ or 0 and $3 \mathrm{~h}$ after indomethacin treatment, respectively. In order to examine the role of TLR4 in inflammasome activation in NSAID-induced enteropathy, mice received an intraperitoneal injection of $0.3 \mathrm{mg} \mathrm{kg}^{-1}$ LPS from Escherichia coli 055:B5 (Sigma-Aldrich) $1 \mathrm{~h}$ after indomethacin treatment or $1 \mathrm{mg} \mathrm{kg}^{-1}$ recombinant human HMGB1 (Sigma-Aldrich ) 0 and $3 \mathrm{~h}$ after indomethacin treatment.

We also investigated the roles of macrophages in the damage. To induce macrophage depletion, mice received an intraperitoneal injection of $200 \mu \mathrm{l}$ of clodronate-encapsulated liposomes (Funakoshi, Tokyo, Japan) $48 \mathrm{~h}$ before indomethacin challenge, as previously reported by others. ${ }^{42}$ Studies were conducted using 4-9 samples. All measurements were performed in a blinded manner.

RNA isolation and determination of the mRNA expression levels of inflammatory cytokines and inflammasome components in the small intestinal tissue using RT-PCR. Total RNA was isolated from intestinal tissue using an ISOGEN kit (Nippon Gene, Tokyo, Japan) according to the manufacturer's protocol. Complementary DNA was produced using the High Capacity RNA-to-cDNA Kit (Life Technologies, Carlsbad, CA) according to the manufacturer's protocol. Real-time quantitative RT-PCR analyses were performed using an Applied Biosystems 7500 Fast Real-Time PCR system and software (Life Technologies). The reaction mixture was prepared according to the manufacturer's protocol using the TaqMan Fast Universal PCR master mixture (Life Technologies). Thermal cycling conditions were as follows: 45 cycles of $95^{\circ} \mathrm{C}$ for $15 \mathrm{~s}$ and $60^{\circ} \mathrm{C}$ for $1 \mathrm{~min}$. The expression levels of IL-1 $\beta$, IL-18, and TNF- $\alpha$, and a number of inflammasome components, including NLRP3, NLRC4, NLRP6, AIM2, ASC, and caspase-1, were quantified in damaged and normal small intestinal tissue using real-time RT-PCR and standardized to TaqMan glyceraldehyde-3-phosphate dehydrogenase (GAPDH; Life Technologies) mRNA levels. The levels of expression of these mRNAs are indicated as ratios to the mean value in normal intestinal tissue. The primers and probes used for RT-PCR are detailed in Supplementary Table S1.

Western blot analysis. Small intestinal tissues were homogenized and lysed on ice in a buffer containing $0.5 \%$ NP-40, 40 mM Tris- $\mathrm{HCl}(\mathrm{pH}$ 8.0), $120 \mathrm{~mm} \mathrm{NaCl}$, phosphatase inhibitor cocktail (PhosSTOP; Roche Applied Science, Indianapolis, IN), and a protease cocktail inhibitor (Complete Mini, Thermo Fisher Scientific). Protein levels in the lysate were measured with the modified bicinchoninic acid method (Thermo Fisher Scientific, Rockford, IL). Proteins were denatured with sodium dodecyl sulfate sample buffer at $95^{\circ} \mathrm{C}$ for $5 \mathrm{~min}$ and then subjected to $15 \%$ sodium dodecyl sulfate-polyacrylamide gel electrophoresis and transferred to polyvinylidene difluoride membrane. Membranes were blocked in Tris-buffered saline buffer $(10 \mathrm{~mm}$ Tris- $\mathrm{HCl}, \mathrm{pH} 7.5$, $100 \mathrm{~mm} \mathrm{NaCl}, 0.1 \%$ Tween-20) containing 5\% skim milk and then incubated overnight with one of the following antibodies: goat anti-IL$1 \beta$ (R\&D Systems), rabbit anti-caspase-1 (Santa Cruz Biotechnology, Santa Cruz, CA), and mouse anti- $\beta$-actin (Sigma-Aldrich). Bound antigen-antibody complexes were detected with the appropriate secondary antibodies coupled to horseradish peroxidase with enhanced chemiluminescence according to the manufacturer's instructions (Amersham, Arlington Heights, IL). Relevant bands were quantified with laser-scanning densitometry and the expression level of each protein was normalized to that of $\beta$-actin. All data are expressed as percent change from control. Independent experiments were performed at least twice.

Measurement of IL-1 $\beta$ and IL-18 concentrations in intestinal tissue. Small intestinal tissue were homogenized in ice-cold lysis buffer (50 mм HEPES, 150 mм NaCl, 10\% glycerol, 1\% Triton X-100, 1.5 mм $\mathrm{MgCl}_{2}, 1 \mathrm{~mm}$ EGTA, $1 \mathrm{~mm}$ sodium vanadate, $10 \mathrm{~mm}$ sodium pyrophosphate, $10 \mathrm{~mm} \mathrm{NaF}, 300 \mu \mathrm{m}$ p-nitrophenyl phosphate, $1 \mathrm{~mm}$ PMSF, $10 \mu \mathrm{g} \mathrm{ml}^{-1}$ leupeptin, and $10 \mu \mathrm{g} \mathrm{ml}^{-1}$ aprotinin) containing phosphatase inhibitor cocktail (PhosSTOP) and a protease cocktail inhibitor (Complete Mini). Homogenates were centrifuged at $14,000 \mathrm{~g}$ for $15 \mathrm{~min}$ and the supernatants were then collected. IL-1 $\beta$ and IL-18 concentrations in the supernatant were measured using ELISA Ready-Set-Go kit for mouse IL-1 $\beta$ (eBioscience, San Diego, CA) and the Mouse IL-18 ELISA kit (MEDICAL \& BIOLOGICAL LABORATORIES, Tokyo, Japan) respectively, following the manufacturers' instructions.

Histological and immunofluorescent studies. The protein levels of IL-1 $\beta$, cleaved caspase- $1, \mathrm{NLRP} 3$, and $\mathrm{P} 2 \mathrm{X}_{7}$ receptor, and their colocalization with macrophages were determined using an immunofluorescent method. The primary antibodies used for immunofluorescent staining included goat polyclonal anti-IL-1 $\beta$ (diluted 1:100; R\&D Systems), goat polyclonal anti-cleaved caspase- 1 p20 (diluted 1:200; Santa Cruz Biotechnology), goat polyclonal antiNLRP3 (diluted 1:500; Abcam), rabbit polyclonal anti-P2X (diluted $_{7}$ 1:500; Alomone Laboratories, Jerusalem, Israel), and rat monoclonal anti-F4/80, a marker for mature macrophage, (diluted 1:500; AbD Serotec, Oxford, UK). Tissue samples were fixed with $0.1 \mathrm{~m}$ phosphate buffer ( $\mathrm{pH} 7.4$ ) containing 4\% paraformaldehyde and embedded in Tissue-Tek OCT Compound (Sakura Finetek Japan, Tokyo, Japan). Serial $6-\mu \mathrm{m}$-thick cryostat sections were mounted on silanized slides (Dako, Tokyo, Japan). Then, the tissue samples were incubated overnight at $4{ }^{\circ} \mathrm{C}$ with the primary antibodies and then reacted with the corresponding secondary fluorescent dye-conjugated antibodies 
(Alexa Fluor; Invitrogen, Carlsbad, CA) for $2 \mathrm{~h}$. For negative controls, the primary antibody was replaced by isotype-matched immunoglobulins. Samples were examined with a confocal microscope equipped with argon and argon-krypton laser sources. Hematoxylin and eosin staining was performed for morphological observations.

Statistical analysis. Values are expressed as means \pm s.e.m. One-way analysis of variance was used to test for significance of differences among treatment group means, and results were analyzed by Fisher's protected least significant difference test. Differences with $P$ values $<0.05$ were considered significant.

SUPPLEMENTARY MATERIAL is linked to the online version of the paper at http://www.nature.com/mi

\section{ACKNOWLEDGMENTS}

We thank Emi Suzuki-Yoshioka for her technical assistance. This study was supported by a MEXT/JSPS KAKENHI grant (no. 25870624 to Y.N.).

\section{DISCLOSURE}

The authors declared no conflict of interest.

c 2016 Society for Mucosal Immunology

\section{REFERENCES}

1. Graham, D.Y., Opekun, A.R., Willingham, F.F. \& Qureshi, W.A. Visible smallintestinal mucosal injury in chronic NSAID users. Clin. Gastroenterol. Hepatol. 3, 55-59 (2005).

2. Sugimori, S. et al. Evaluation of small bowel injury in patients with rheumatoid arthritis by capsule endoscopy: effects of anti-rheumatoid arthritis drugs. Digestion 78, 208-213 (2008).

3. Goldstein, J.L. et al. Video capsule endoscopy to prospectively assess small bowel injury with celecoxib, naproxen plus omeprazole, and placebo. Clin. Gastroenterol. Hepatol. 3, 133-141 (2005).

4. Maiden, L., Thjodleifsson, B., Theodors, A., Gonzalez, J. \& Bjarnason, I. A quantitative analysis of NSAID-induced small bowel pathology by capsule enteroscopy. Gastroenterology 128, 1172-1178 (2005).

5. Wallace, J.L. et al. Proton pump inhibitors exacerbate NSAID-induced small intestinal injury by inducing dysbiosis. Gastroenterology 141, 1314-1322 (2011).

6. Watanabe, T. et al. Risk factors for severe nonsteroidal anti-inflammatory drug-induced small intestinal damage. Dig. Liver Dis. 45, 390-395 (2013).

7. Watanabe, T. et al. Non-steroidal anti-inflammatory drug-induced small intestinal damage is Toll-like receptor 4 dependent. Gut 57, 181-187 (2008).

8. Nadatani, Y. et al. High mobility group box 1 promotes small intestinal damage induced by nonsteroidal anti-inflammatory drugs through Toll-like receptor 4. Am. J. Pathol. 181, 98-110 (2012).

9. Fukumoto, K. et al. Role of tumor necrosis factor-alpha in the pathogenesis of indomethacin-induced small intestinal injury in mice. Int. J. Mol. Med. 27, 353-359 (2011).

10. Watanabe, T. et al. Anti-tumour necrosis factor agents reduce nonsteroidal anti-inflammatory drug-induced small bowel injury in rheumatoid arthritis patients. Gut 63, 409-414 (2014).

11. Cominelli, F. et al. Interleukin 1 (IL-1) gene expression, synthesis, and effect of specific IL-1 receptor blockade in rabbit immune complex colitis. J. Clin. Invest. 86, 972-980 (1990).

12. Watanabe, T., Arakawa, T., Fukuda, T., Higuchi, K. \& Kobayashi, K. Role of neutrophils in a rat model of gastric ulcer recurrence caused by interleukin1 beta. Am. J. Pathol. 150, 971-979 (1997).

13. Watanabe, T., Higuchi, K., Tominaga, K., Fujiwara, Y. \& Arakawa, T. Acid regulates inflammatory response in a rat model of induction of gastric ulcer recurrence by interleukin 1beta. Gut 48, 774-781 (2001).

14. Martinon, F. \& Tschopp, J. Inflammatory caspases: linking an intracellular innate immune system to autoinflammatory diseases. Cell 117, 561-574 (2004).

15. Yu, H.B. \& Finlay, B.B. The caspase- 1 inflammasome: a pilot of innate immune responses. Cell Host Microbe 4, 198-208 (2008).
16. Hornung, V. et al. AIM2 recognizes cytosolic dsDNA and forms a caspase-1-activating inflammasome with ASC. Nature 458, 514-518 (2009).

17. Franchi, L., Munoz-Planillo, R. \& Nunez, G. Sensing and reacting to microbes through the inflammasomes. Nat. Immunol. 13, 325-332 (2012).

18. Bauernfeind, F.G. et al. Cutting edge: NF-kappaB activating pattern recognition and cytokine receptors license NLRP3 inflammasome activation by regulating NLRP3 expression. J. Immunol. 183, 787-791 (2009).

19. Park, E. et al. Activation of NLRP3 and AIM2 inflammasomes by Porphyromonas gingivalis infection. Infect. Immun. 82, 112-123 (2014).

20. Zaki, M.H. et al. The NLRP3 inflammasome protects against loss of epithelial integrity and mortality during experimental colitis. Immunity $\mathbf{3 2}$, 379-391 (2010).

21. Elinav, E. et al. NLRP6 inflammasome regulates colonic microbial ecology and risk for colitis. Cell 145, 745-757 (2011).

22. Elinav, E., Henao-Mejia, J. \& Flavell, R.A. Integrative inflammasome activity in the regulation of intestinal mucosal immune responses. Mucosal Immunol. 6, 4-13 (2013).

23. Dinarello, C.A. et al. Overview of interleukin-18: more than an interferongamma inducing factor. J. Leukoc. Biol. 63, 658-664 (1998).

24. Lamkanfi, M. \& Dixit, V.M. Mechanisms and functions of inflammasomes. Cell 157, 1013-1022 (2014).

25. Wen, H., Miao, E.A. \& Ting, J.P. Mechanisms of NOD-like receptorassociated inflammasome activation. Immunity 39, 432-441 (2013).

26. Kawaguchi, M. et al. Inflammasome activation of cardiac fibroblasts is essential for myocardial ischemia/reperfusion injury. Circulation 123, 594604 (2011).

27. Grailer, J.J. et al. Critical role for the NLRP3 inflammasome during acute lung injury. J. Immunol. 192, 5974-5983 (2014).

28. Inoue, Y. et al. NLRP3 regulates neutrophil functions and contributes to hepatic ischemia-reperfusion injury independently of inflammasomes. $J$. Immunol. 192, 4342-4351 (2014).

29. Zhuang, Y. et al. NLRP3 inflammasome mediates albumin-induced renal tubular injury through impaired mitochondrial function. J. Biol. Chem. 289, 25101-25111 (2014).

30. Bauer, C. et al. Colitis induced in mice with dextran sulfate sodium (DSS) is mediated by the NLRP3 inflammasome. Gut 59, 1192-1199 (2010).

31. Siegmund, B., Lehr, H.A., Fantuzzi, G. \& Dinarello, C.A. IL-1 beta converting enzyme (caspase-1) in intestinal inflammation. Proc. Natl. Acad. Sci. USA 98, 13249-13254 (2001).

32. Zhang, J., Fu, S., Sun, S., Li, Z. \& Guo, B. Inflammasome activation has an important role in the development of spontaneous colitis. Mucosal Immunol. 7, 1139-1150 (2014).

33. Allen, I.C. et al. The NLRP3 inflammasome functions as a negative regulator of tumorigenesis during colitis-associated cancer. J. Exp. Med. 207, 1045-1056 (2010).

34. Hirota, S.A. et al. NLRP3 inflammasome plays a key role in the regulation of intestinal homeostasis. Inflamm. Bowel Dis. 17, 1359-1372 (2011).

35. Dupaul-Chicoine, J. et al. Control of intestinal homeostasis, colitis, and colitis-associated colorectal cancer by the inflammatory caspases. Immunity 32, 367-378 (2010).

36. Sutterwala, F.S., Haasken, S. \& Cassel, S.L. Mechanism of NLRP3 inflammasome activation. Ann. NY Acad. Sci. 1319, 82-95 (2014).

37. Broz, P. \& Monack, D.M. Molecular mechanisms of inflammasome activation during microbial infections. Immunol. Rev. 243, 174-190 (2011).

38. Franchi, L., Eigenbrod, T. \& Nunez, G. Cutting edge: TNF-alpha mediates sensitization to ATP and silica via the NLRP3 inflammasome in the absence of microbial stimulation. J. Immunol. 183, 792-796 (2009).

39. Kahlenberg, J.M. \& Dubyak, G.R. Mechanisms of caspase- 1 activation by P2X7 receptor-mediated K + release. Am. J. Physiol. Cell Physiol. 286, C1100-C1108 (2004).

40. Ferrari, D. et al. The P2X7 receptor: a key player in IL-1 processing and release. J. Immunol. 176, 3877-3883 (2006).

41. Iyer, S.S. et al. Necrotic cells trigger a sterile inflammatory response through the Nlrp3 inflammasome. Proc. Natl. Acad. Sci. USA 106, 20388-20393 (2009).

42. Lee, S. et al. Distinct macrophage phenotypes contribute to kidney injury and repair. J. Am. Soc. Nephrol. 22, 317-326 (2011). 